\title{
A Novel Approach of Renewable Energy Powered Hybrid Electrical Vehicle Using BLDC Motor
}

\author{
Ch. UmaMaheshwarRao ${ }^{1}$, K.Suresh ${ }^{2}$, A. Naveen Reddy ${ }^{3}$ \\ ${ }^{l}$ VFSTR University, Guntur, Andhra Pradesh, India \\ ${ }^{2}$ VFSTR University, Guntur, Andhra Pradesh, India \\ ${ }^{3}$ VFSTR University, Guntur, Andhra Pradesh, India \\ *Corresponding author E-mail: maheshsrkr@gmail.com
}

\begin{abstract}
Renewable energy based hybrid electrical vehicle (HEV) has been useful to make clean and green environment. Solar energy is a vailable during day time which feed energy to run HEV and opposite wind energy also one of the input and it also useful to feed energy input to the vehicle. In the existing system of hybrid powered vehicles are not utilizing this energy properly due to some drawbacks related to blade stiffness, vehicle friction torque and efficiency. This proposed system overcome those difficulties and supply the power very conveniently. The noveltyof this paper is wind extraction; this system of approach is very helpful to convert the available opposite wind to the vehicle into useful energy. Wind outlet provisions are also available to reduce vehicle friction torque. The power sources such as solar, wind and fuel cell and the appliances of the car made sophisticated, which are controlled by a universal controller. The BLDC motor controlled by fuzzy PID concept of making the system is so reliable and control all the system operations effectively.
\end{abstract}

Keywords: Novel wind extractor, BLDC, Solar and PID controller.

\section{Introduction}

Future fuel consumption growth of vehicle in the world is kept on increasing $2 \%$ per year [9]. In the upcoming years of next four decades, the electrical powered vehicle requirement is essential to compensate fuel demand and also this is very helpful for living things. Present electrical demand in the world is $15 \mathrm{TW}$; it is growing upto $30 \mathrm{TW}$ approximately [1]. Electrical energy requirement has been fulfilling from natural resources of fossil fuels and other minerals by non-renewable type of power extraction. This form of power generation is very harmful for living things; the pollution outlet of non-renewable thermal plant is $37 \%$ of $\mathrm{So}_{2}$ and $20 \%$ of other gases, which are making dangerous things [10]. Coal conversion efficiency also only $10 \%$ and it produce ashes \& other dust particles and its final efficiency are 40\% [2].

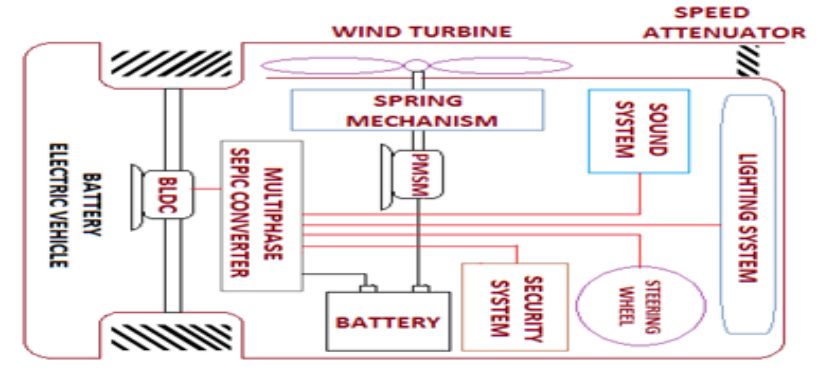

Fig. 1. Proposed renewable energy powered vehicle

This form of power generation does not helpful for living things itscreates environmental pollution and increases the global warming, which leads to create acid rain [3]. Main drawback of conven- tional form of power generations are less efficiency, air pollution, global warming and the power generation also in remote areas or non-people living areas, which required huge materials to transmit power to the load centre [7].

The conventional form of electric vehicle powered from some charging stations, the problem of this method is charging time, the vehicle should wait until the charge will complete to $100 \%$ [4] [5] and [6]. To overcome this drawback some solar powered electric vehicle was introduced by some researchers, the drawback related to the research is non-reliable, during night time and cloudy day's source is not possible. Here the proposed research work introduced $100 \%$ renewable powered electric vehicle, which is highly reliable from three different sources, the sources are solar, wind and spring mechanism. Device which converts solar into electrical energy is known as photo-voltaic device which working under photo-voltaic principle is too fixed in the roof of the vehicle, likewise wind energy extractor placed in side of the vehicle. This novel method of extraction is the main work which produces more electrical and helps to drive the vehicle effectively.

\section{Closed loop control of BLDC based vehicle drive}

Closed loop control of BLDC based vehicle drive is as shown in Figure 2. It minimizes the complexities related to the existing control vehicle drive system. Proposed vehicle drive consists of two control loops, the outer loop is position control and the inner loop is for current control. This type of control system design is simple and this proposed drive consists of Fuzzy PID (FPID) con- 
troller, which improves the drive performance. The proposed vehicle drive has DC-link current in the place of three phase currents to reduce the implementation cost.

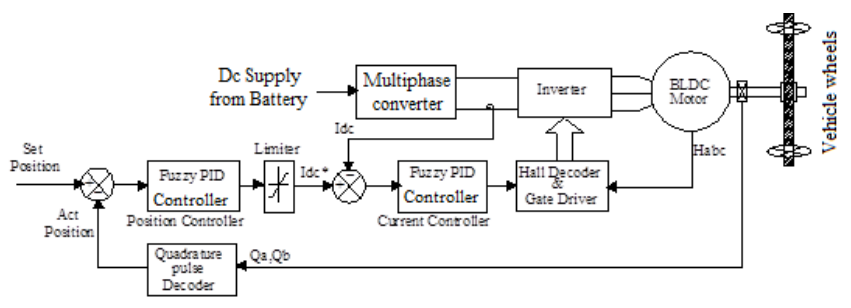

Fig. 2: Closed loop control for renewable energy powered vehicle

FPID controller is suitablefor this proposed vehicle drive is as shown in Figure 3. FPID is the combination ofFPI and FPD controllers, Measurement changes (CE) and Error (E)

$\mathrm{E}=$ set value - actual value $\& \mathrm{CE}=$ (present sample - previous sample) measurement.

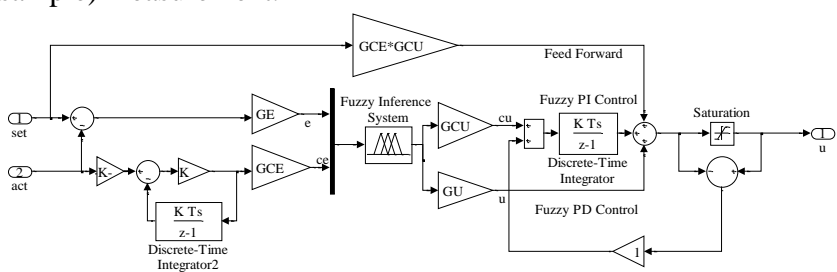

Fig. 3: FPID controller

FPID controller is designed and analysedby usingFuzzy Logic Toolbox in MATLAB/SIMULINK software. In this software have separate FIS (Fuzzy Inference System) and Graphical User Interface (GUI) to design the Fuzzy Logic Controllers (FLC). One of the FIS is Mamdani and defuzzification method is centre of gravity, which consist of two inputs and one output is constructed as shown in Figure 4.

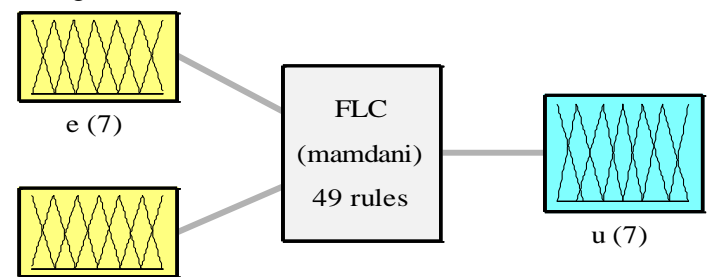

ce (7) System FLC: 2 inputs, 1 outputs, 49 rules

Fig.4: Mamdani FIS

Input and output variables were mapped by a Membership Function (MF) to work with FIS. Generally using triangular MF with a cross neighbour set of MF value of 0.5 is as shown in Figure 5 for a input variable error ' $E$ '.

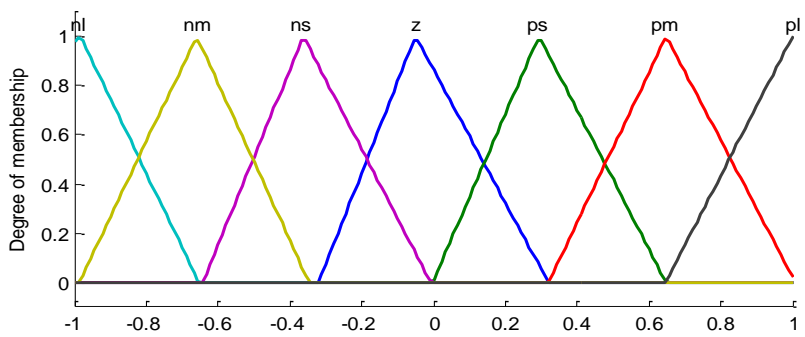

Fig. 5: Membership function of input variable ' $e$ '

The linguistic variables are divided into seven groups; the range of $\mathrm{MF}$ is used as standard form of unity \pm 1 . Other variable MF of $\mathrm{CE}$ as shown in Figure 6 and output control signal ' $u$ ' as shown in Figure 8 are same in structures of universal standards.

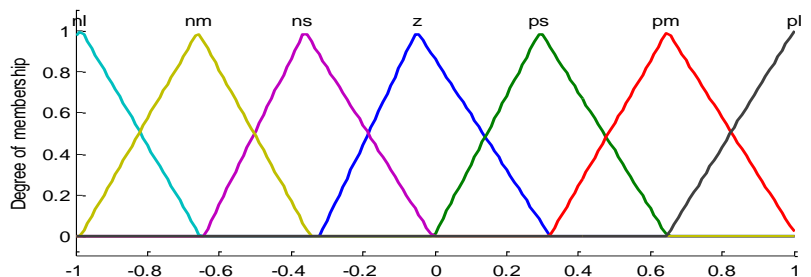

Fig. 6: Membership function of input variable 'ce'

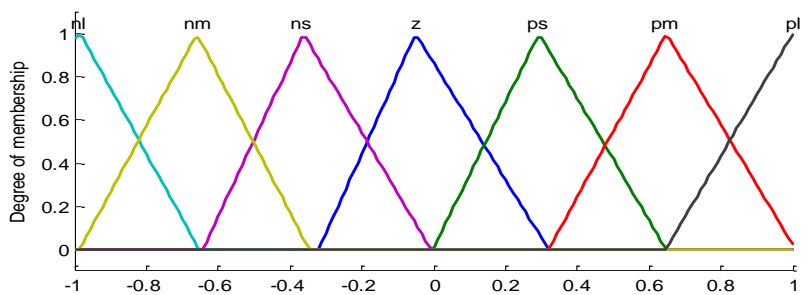

Fig.7: Membership function of output variable ' $u$ '

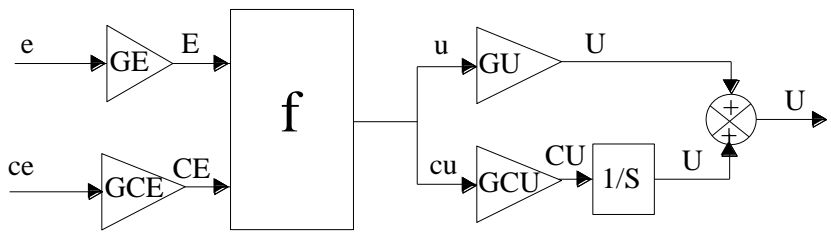

Rule base

Fig.8: Fuzzy PID controller

$U_{n}(F P I D)=U_{n}(F P I)+U_{n}(F P D)$

$U_{n}(F P I D)=\left(G C U * G C E * E_{n}+G C U * G E * \sum_{i=1}^{n} E_{i} T_{s}\right)$

$+\left(G U * G E * E_{n}+G U * G C E * \frac{E_{n}-E_{n-1}}{T_{s}}\right)$

$U_{n}(F P I D)=(G C U * G C E+G U * G E) * E_{n}$

$+(G C U * G E) * \sum_{i=1}^{n} E_{i} T_{s}+(G U * G C E) * \frac{E_{n}-E_{n-1}}{T_{s}}$

$K_{p}=G C U * G C E+G U * G E$

$K_{i}=G C U * G E$

$K_{d}=G U * G C E$

Output of fuzzy PID controller is as per equation 1. The Fuzzy PID controller and membership function of output variables are shown in figures 7 and 8 . Equations $2,3 \& 4$ are computed for PID controllers gain. From the Equations 5 to 8 , the fuzzy scaling factors are determined from the known conventional PID controller gain values as listed in Table 1.

$G E=\frac{1}{\max . e r r o r}$

$G C E=G E *\left(K_{p}-\sqrt{K_{p}^{2}-4 K_{i} K_{d}}\right) \frac{K_{i}}{2}$

$G C U=\frac{K_{i}}{G E}$ 


$$
G U=\frac{K_{d}}{G C E}
$$

Table 1: Designed fuzzy scaling factors

\begin{tabular}{|l|l|}
\hline Position controller & Current controller \\
\hline GE $=\mathbf{0 . 0 0 2}$ & GE $=00.17$ \\
\hline GCE $=\mathbf{0 . 0 5 7}$ & GCE $=00.35$ \\
\hline GCU $=\mathbf{8 . 7 0 3}$ & GCU $=\mathbf{0 4 . 1 0}$ \\
\hline GU $=\mathbf{2 9 . 0 3 4}$ & GU $=\mathbf{1 6 . 0 0}$ \\
\hline
\end{tabular}

\section{Results and discussion}

A closed loop Speed control of BLDC Motor by Fuzzy PID is simulated with BLDC motor model in state space modelling, transfer equation and transfer equations. The proposed BLDC motor is simulated as per data sheets tables as shown in table. II. A 24V Faulshaber 3564024B series and their specified data sheet information's are used for simulation with corresponding system variables. Battery with inverter and BLDC motor module is taken form Simulink library block sets and their settings has been changed as per our requirements. The design of BLDC motor is verified using parameters listed in TableII and modelled in MATLAB SIMULINK environment to verify design analysis of Brushless DC motor. A Faulhaber BLDC motor (Series2444024B)[10] and Motor driver rated current 6A peak have been taken for simulation with BLDC motor is set value of 10000rpm speed and simulated performance of motor at no load and loaded condition is presented.

Table2: BLDC motor parameters

\begin{tabular}{|l|l|l|l|}
\hline Motor parameter & Symbol & Values & Units \\
\hline Nominal Voltage & $\mathrm{Vn}$ & 24 & Volt \\
\hline Output power & $\mathrm{P}_{2 \max }$ & 101 & Watts \\
\hline Speed constant & $\mathrm{Kn}$ & 475 & $\mathrm{Rpm} / \mathrm{V}$ \\
\hline Current constant & $\mathrm{Ki}$ & 0.050 & $\mathrm{~A} / \mathrm{mNm}$ \\
\hline Back EMF constant & $\mathrm{KE}$ & 2.107 & $\mathrm{mV} / \mathrm{rpm}$ \\
\hline Stall torque & $\mathrm{MH}$ & 371 & $\mathrm{mNM}$ \\
\hline Friction torque, Static & $\mathrm{Co}$ & 1.10 & $\mathrm{mNm}$ \\
\hline Friction torque, dynamic & $\mathrm{Cv}$ & $2.4 * \mathrm{e}-4$ & $\mathrm{mNm} / \mathrm{rpm}$ \\
\hline Torque constant & $` \mathrm{Km}$ & 20.12 & $\mathrm{mNM} / \mathrm{A}$ \\
\hline
\end{tabular}

Faulhaber BLDC Motor with model 3564B series is designed in MATLAB based on transfer function, state space modelling and transfer equations in open-loop condition and results is presented in fig.9. The Motor characteristic of each modelling method is tabulated below in Table III.
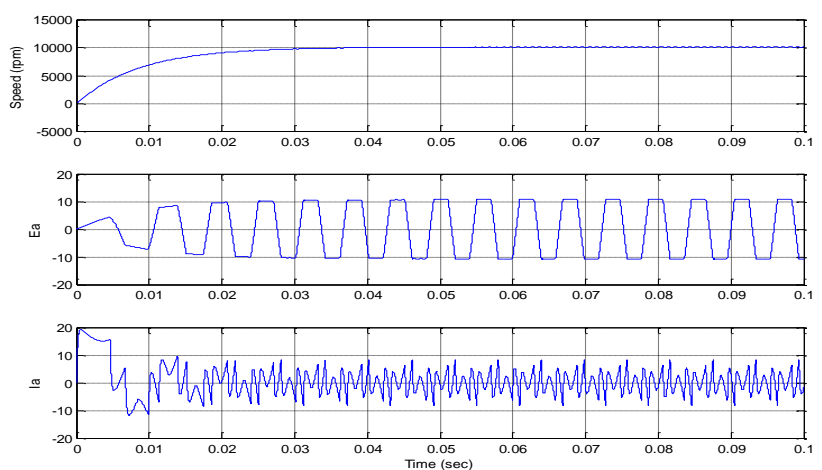

Fig.9: Output waveform of BLDC motor model in transfer functions

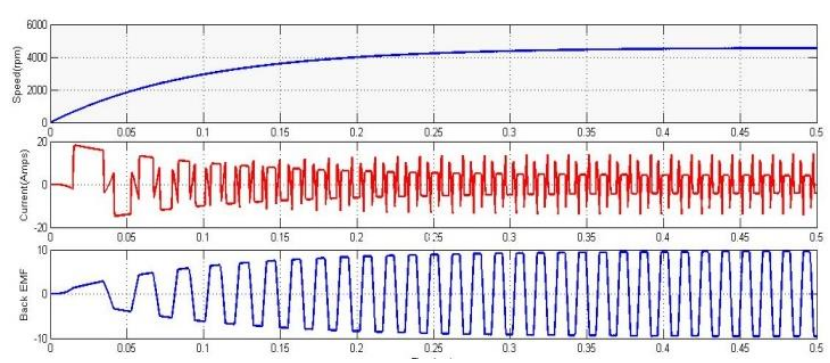

Fig.10: Output waveform of BLDC motor model in transfer equations

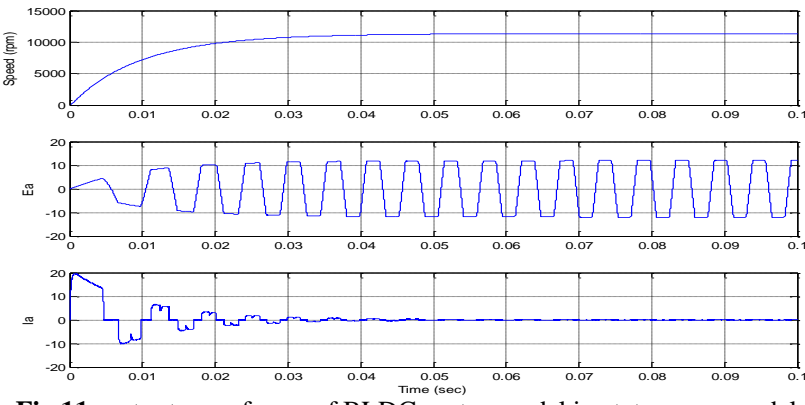

Fig.11: output waveforms of BLDC motor model in state space model

Six PWM gate pulses are generated as per decoding logic in both directions. For $120^{\circ}$ conduction mode of inverter operation, observed results clearly show the phase delay between $\mathrm{Q}_{1}$ and $\mathrm{Q}_{2}$ is $60^{\circ}$ electrical for rest. If motor rotates clockwise, then gate pulse $\mathrm{Q}_{3}$ lags $\mathrm{Q}_{1} 120^{\circ}$ electrically. If motor rotates counter clockwise, then gate pulse $\mathrm{Q}_{3}$ leads $\mathrm{Q}_{1} 120^{\circ}$ electrically. Likewise all the gate pulses are verified.

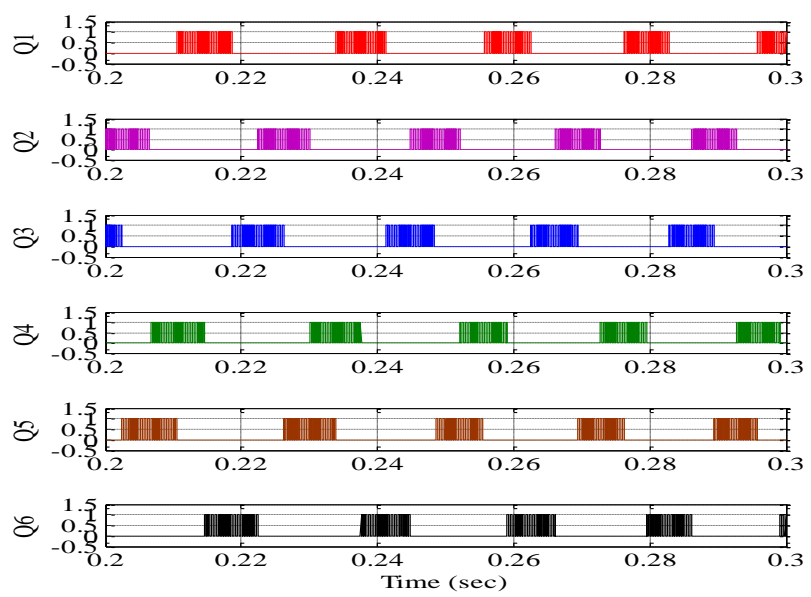

Fig.12: Gate pulse for inverter
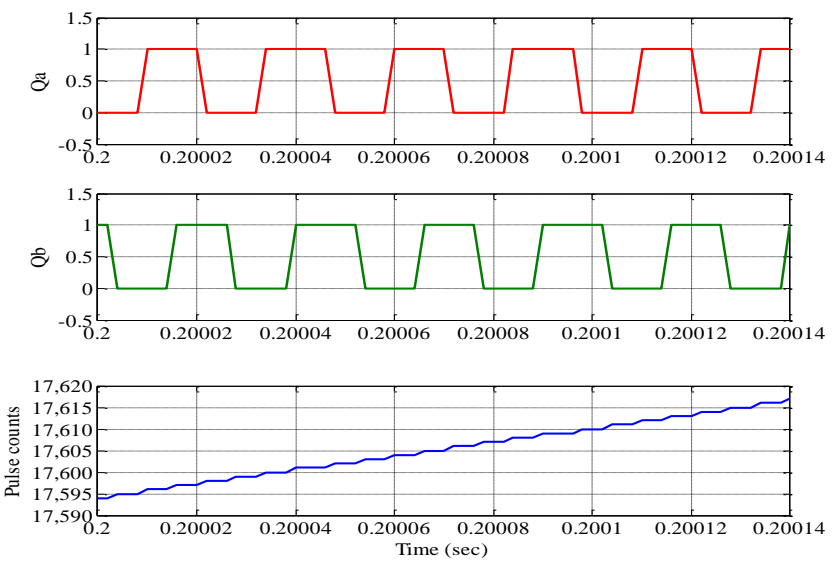

Fig.13: QEP Signal
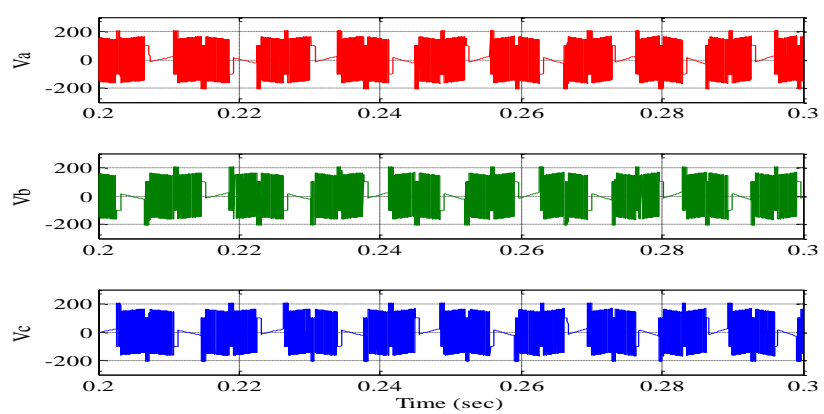

Fig.14: Phase voltage 

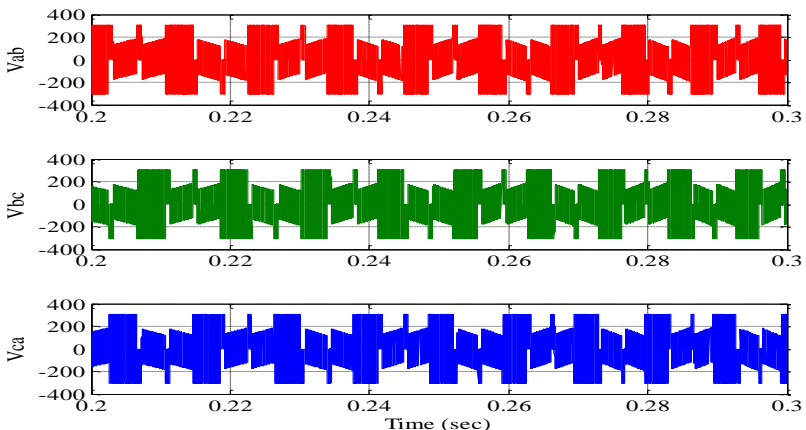

Fig.15: Line Voltage

포
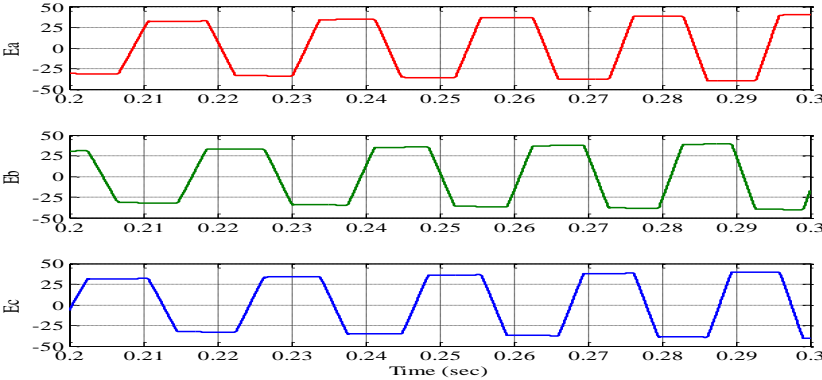

Fig.16: Back EMF

Table III BLDC Motor modelling comparison

\begin{tabular}{|l|c|c|c|}
\hline Parameters & $\begin{array}{c}\text { Transfer } \\
\text { Function }\end{array}$ & $\begin{array}{c}\text { Transfer } \\
\text { equations }\end{array}$ & $\begin{array}{c}\text { State Space } \\
\text { Modeling }\end{array}$ \\
\hline Speed (11300rpm) & 4000 range & Achieved & Achieved \\
\hline $\begin{array}{l}\text { Dynamic Characteris- } \\
\text { tics } \\
\text { (settling time to reach } \\
\text { rated speed) }\end{array}$ & Slow & Moderate & Fast \\
\hline $\begin{array}{l}\text { Back EMF (Pure } \\
\text { Trapezoidal) }\end{array}$ & Achieved & Achieved & Achieved \\
\hline Current (quasi Square) & N.A & N.A & Achieved \\
\hline $\begin{array}{l}\text { PWM Current control } \\
\text { (IaIbIc ) }\end{array}$ & N.A & Achieved & Achieved \\
\hline $\begin{array}{l}\text { Hysterias Current } \\
\text { control (IaIbIc })\end{array}$ & Achieved & Achieved & Achieved \\
\hline $\begin{array}{l}\text { PWM Current control } \\
\text { (Idc })\end{array}$ & N.A & N.A & Achieved \\
\hline $\begin{array}{l}\text { Hysterias current } \\
\text { Controller(Idc })\end{array}$ & N.A & N.A & Achieved \\
\hline
\end{tabular}

As in case of transfer function from fig. 10 speed is achieved moderately with better dynamic characteristics compare to transfer equations and existence of poor current distortion. From fig.11 the state space modelling holds fast dynamic performance and speed achieved with rated value and generates pure quasi-square waveform to drive BLDC motor effectively. Gate pulse of the inverter, QEP signal, Back EMF, Phase voltage and line voltage are shown in the figures 12 to figure 16. Powergui block in MATLAB has automatically converted the MATLAB-model into average model in SIMULINK which is not possible in transfer function and State-space modelling of BLDC motor.

\section{Conclusion}

The performance of the evaluation results show that, such a modelling is very useful in studying the drive system before taking up the dedicated controller design, accounting the relevant dynamic parameters of the motor. The paper presents an implementation of BLDC motor dynamic model, by using the transfer functions, transfer equations and state space modelling using MATLABSIMULINK in which all methods performed well and every method has its drawbacks. An inverter mathematical model is also simulated in MATLAB-SIMULINK with corresponding encoder current controller.

\section{References}

[1] Ong, C.M., 1998. "Dynamic simulation of electric machinery using MATLAB/SIMULINK". 1st edn. Prentice hall PTR, New Jersey, ISBN: 0137237855.

[2] T.J.E Miller, Brushless Permanent-Magnet and Reluctance Motor Drives, Oxford Science Publisher, U.K, 1989

[3] T. Kenjo and S. Nagamori, Permanent Magnet Brushless DC Motors. Oxford, U.K.: Clarendon, 1985

[4] PadmarajaYedamale, "Brushless DC (BLDC) Motor Fundamentals", Microchip Technology Inc., 2003.

[5] S. Baldursson, "BLDC Motor Modelling and Control - A MATLAB/Simulink Implementation", Master Thesis, May, 2005.

[6] B. Tibor, V. Fedák and F. Durovský, "Modeling and simulation of the BLDC motor in MATLAB GUI," 2011 IEEE International Symposium on Industrial Electronics, Gdansk, 2011, pp. 1403 1407.doi: 10.1109/ISIE.2011.5984365

[7] Singh, C. P.; Kulkarni, S. S.; Rana, S. C.andKapilDeo, "State-Space Based Simulink Modeling of BLDC Motor and its Speed Control using Fuzzy PID Controller", International Journal of Advances in Engineering Science and Technology, Vol. 2 , No. 3, 2013, pp. 359 369.

[8] Suresh, K \&Arulmozhiyal, R, 'Design and implementation of bidirectional dc-dc converter for wind energy system', Circuits and Systems, E-ISSN 2153-1285, P-ISSN 2153-1293, vol. 7, pp. 37053722, 2016.

[9] A. A. Laczko, M. V. Zaharia, M. M. Radulescu and S. Brisset, "Modeling and simulation of a brushless DC permanent-magnet generator-based wind energy conversion system," Ecological Vehicles and Renewable Energies (EVER), 2015 Tenth International Conference on, Monte Carlo, 2015, pp. 1-7. doi: 10.1109/EVER.2015.7113021

[10] J. Gebauer, D. Fojtík and P. Podešva, "Modeling of the electronic variable pitch drive," Carpathian Control Conference (ICCC), 2015 16th International, Szilvasvarad, 2015, pp. 138-141. doi: 10.1109/CarpathianCC.2015.7145062.

[11] FaulhaberMiniatureDriveSystems,www.faulhaber.com

[12] Copeland Brian R., "The Design of PID Controllers using Ziegler Nichols Tuning", March 2008.

[13] G. Brandli and M. Dick, "Alternatingcurrent fed power supply," U.S.Patent 4084 217, Nov.4,1978. 